удК 332.851

В. И. Самаруха

Байкальский государственный университет, г. Иркутск, Российскал Федераиия

Т. Г. Краснова

Хакасский государственный университет ил. Н. Ф. Катанова, 2. Абакан, Российская Федерация

А. С. Вильгельм

Хакасский государственный университет ил. Н. Ф. Катанова, 2. Абакан, Российская Федерация

\title{
ИССЛЕДОВАНИЕ ФАКТОРОВ СПРОСА И ПРЕДЛОЖЕНИЯ НА ЛОКАЛЬНОМ РЫНКЕ ИНДУСТРИАЛЬНОГО ДОМОСТРОЕНИЯ В ПРОЦЕССЕ ФОРМИРОВАНИЯ СТРАТЕГИИ СБАЛАНСИРОВАННОСТИ РАЗВИТИЯ ЭКОНОМИКИ СИБИРСКИХ РЕГИОНОВ
}

\begin{abstract}
АНнотАция. В условиях, когда строительная отрасль становится драйвером роста региональной экономики, тема исследования локальных рынков стройиндустрии становится особенно актуальной. В стройиндустрии Сибири имеющиеся производственные мощности недостаточно загружены и их структура не согласуется со сбалансированным жилищным воспроизводством. Для повышения эффективности взаимодействия сопряженных локальных рынков в статье выделены факторы, оказывающие влияние на спрос и предложение, проведена их систематизация и предложена система показателей оценки потенциала строительной отрасли и критерии оптимизации параметров развития локальных рынков. На основе апробации разработанной методики оценки локального рынка индустриального домостроения в регионе в целях управления, предложена модель стратегии сбалансированного развития локальных рынков регионов Сибири, которая позволяет выбрать приоритетные локализованные зоны для комплексного освоения территорий в зависимости от степени развития потенциала. Доказана применимость разработанной и апробированной методики для исследования локальных рынков в процессе управления сбалансированным социально-экономическим развитием сибирских регионов.

кЛючЕВЫЕ словА. Региональное экономическое развитие; спрос на жилье; предложение жилья и рынки жилья; локальные рынки.

ИНФОРМАЦИЯ О СТАТЬЕ. Дата поступления 31 января 2018 г.; дата принятия к печати 19 марта 2018 г.; дата онлайн-размещения 09 апреля 2018 г.
\end{abstract}

V. I. Samarukha Baikal State University, Irkutsk, Russian Federation

T. G. Krasnova

N. F. Katanov Khakaass State University, Abakan, Russian Federation

A. S. Vilgelm

N. F. Katanov Khakaass State University, Abakan, Russian Federation

\section{STUDY OF SUPPLY AND DEMAND FACTORS ON LOCAL MARKET OF INDUSTRIAL HOUSING CONSTRUCTION IN PROCESS OF FORMING A STRATEGY OF BALANCED DEVELOPMENT OF ECONOMY IN SIBERIAN REGIONS}

ABSTRACT. The topic of the local markets research in the construction industry becomes especially relevant when the construction industry is a growth driver of the

(C) В. И. Саларуха, Т. Г. Краснова, А. С. Вильгельм, 2018

\section{Baikal Research Journal}

электронный научный журнал Байкальского государственного университета 
regional economy. The available production capacities of the Siberian construction industry are not fully loaded and their structure is not consistent with a balanced housing reproduction. In order to increase the effectiveness of the conjugated local markets interaction, the article identifies the factors that influence the demand and supply, systematizes them and offers a system of indicators for assessing the potential of the construction industry and the criteria for optimizing the parameters for development of local markets. Based on approbation of the developed methodology for assessing the local market of the industrial housing construction in the region for management purposes, the model of a balanced development strategy for local markets of Siberian Regions is proposed, which allows to select the priority localized zones for the integrated development of territories, depending on the degree of potential development. The article proves the applicability of the developed and tested methodology for studying the local markets in the process of managing balanced social and economic development of the Siberian regions.

KEYWORDS. Regional economic development; housing demand; housing supply and markets; local markets.

ARTICLE INFO. Received January 31, 2018; accepted March 19, 2018; available online April 09, 2018.

Дисбаланс спроса и предложения, как указано в Стратегии развития промышленности строительных материалов РФ, является одной из основных негативных тенденций, характеризующих развитие локального рынка строительных материалов. Причина заключается в том, что существующая модель взаимодействия субъектов локального рынка строительных материалов приблизилась к пределам своего развития, т.к. имеющиеся производственные мощности не согласуются со сбалансированной структурой жилищного воспроизводства.

Президентом России В. В. Путиным была отмечена перспектива строительной отрасли стать драйвером роста региональных экономик, но для этого необходимо реализовать ее потенциал посредством формирования эффективной системы управления развитием индустриального домостроения. В итоге это должно привести к улучшению делового климата, развитию конкуренции и активному внедрению современных инновационных технологий и материалов в регионах с большим потенциалом своего развития, в частности, в Сибири. По мнению российского экономиста, академика РАН В. В. Ивантера, сибирские регионы с эндогенными источниками развития эффективнее будут генерировать экономический рост через инфраструктурные проекты, направленные на повышение связанности, межрегиональной интеграции, территориальной трудовой мобильности и повышения доступности услуг социальной инфраструктуры [1, с. 21]. Государственная долгосрочная политика в основном исходит из того, что развитие России в ближайшие десятилетия будет определяться теми процессами, которые происходят в Сибири ${ }^{1}$. Производственные мощности сибирских предприятий не загружены полностью, что, по мнению российского экономиста, академика РАН С. Ю. Глазьева, говорит о необходимости внедрения средств индикативного планирования реализации смешанной стратегии развития, при которой эффективность инвестиционной деятельности будет зависеть от структуры производительности факторов производства [2, с. 15]. Инвестиционную привлекательность регионов Сибири характеризуют такие схожие экономические, географические, исторические, культурные и иные признаки как:

- близость к рынкам Азиатско-Тихоокеанской экономической зоны (emerging markets);

${ }^{1}$ Стратегия социально-экономического развития Сибири до 2020 года : утв. распоряжением Правительства РФ от 05 июля 2010 № 1120-р. // Собрание законодательства РФ. 2010. № 33. Ст. 4444.

\section{Baikal Research Journal}


- исторически большая подготовленность к реиндустриализации, чем например Дальний Восток или Арктическая зона РФ;

- пространственное расположение относительно других федеральных округов характеризует транзитный характер потоков межрегиональной логистики;

- огромные территории и низкая плотность населения, огромные расстояния между городам и риски, связанные со слабой инфраструктурой [3, с. 160];

- низкая эффективность сельского хозяйства в области растениеводства (зона рискованного земледелия);

- богатство ресурсов и неосвоенность запасов полезных ископаемых.

Опыт регионов показывает, что актуальность исследования рынка местных строительных материалов заключается в обеспечении взаимосвязи природно-ресурсного потенциала, программ развития отраслей промышленности, строительства и территорий с социально-экономическим развитием региональной экономики с целью повышения жилищной обеспеченности населения региона как элемента роста качества жизни [4, с. $179 ; 5$, с. 39].

К факторам сбалансированности развития региональной экономики относятся идеальная пропорциональность между спросом и предложением на локальных рынках ресурсов, капитала, товаров и услуг, обеспечивающих стабильный прирост валового регионального продукта, инвестиций и повышения качества жизни населения региона [3, с. 160]. Одним из локальных рынков региона, ярко иллюстрирующих данные процессы, является локальный рынок индустриального домостроения. Уровень предложения на данном рынке характеризуется оценкой потенциала развития стройиндустрии региона. Однако представленные в литературе методики не учитывают с помощью всех известных показателей потенциал развития отрасли в соответствии со сбалансированным жилищным воспроизводством.

Основой развития локального рынка строительных материалов региона является потенциал строительной отрасли. Его оценки, как таковой, в рамках взаимодействия сопряженных локальных рынков для обеспечения сбалансированного регионального развития в настоящее время не проводится, так как отсутствуют единая методика и научно обоснованные способы и подходы к такой оценке. Для комплексного анализа факторов разработанная в [6, с. 120] система показателей оценки потенциала развития строительной отрасли учитывает влияние развития локального рынка стройиндустрии региона на его сбалансированное развитие [7, с. 261].

Спрос на локальном рынке стройиндустрии в конечном итоге определяется факторами территориально локализованного платежеспособного жилищного спроса. Предложение характеризуется ресурсным потенциалом развития отрасли. Локализация оказывает влияние на уровень транспортных и складских затрат, поэтому размещение объектов стройиндустрии должна разрабатываться на основе комплексных программ развития региона [8, с. 468]. В целом методика анализа локального рынка представляет собой факторно-ресурсный подход к достижению сбалансированности развития отрасли региона и проводит оценку по семи ключевым направлениям - компонентам потенциала отрасли индустриального домостроения:

- производственная, характеризующая общую производственную структуру отрасли региона;

- трудовая, отражающая особенности занятости и трудомиграционных потоков региона;

- ресурсная, оценивающая величину минерально-сырьевой базы общераспространенных и специфических полезных ископаемых региона;

\section{Baikal Research Journal}


- инфраструктурная, позволяющая определить потенциал развития таких субъектов локального рынка как локализованные торговые и торгово-посреднические организации; кредитно-финансовые учреждения; транспортные организации; консалтинговые и экспертные организации; контролирующие и надзорные органы; организации по оказанию услуг; юридические организации;

- инвестиционная, позволяющая оценить уровень инвестиционной активности развития отрасли;

- инновационная, оценивающая степень внедрения и использования новейших материалов и технологий в индустриальном домостроении;

- экологическая, характеризующая качество окружающей среды, на которое влияет сектор стройиндустрии.

На основании вышеизложенного выявлены, описаны и сгруппированы основные факторы, оказывающие влияние на спрос и предложение на локальном рынке строительных материалов сибирских регионов (табл. 1).

Факторы, оказываюшие влияние на спрос и предложение

Таблица 1 на локальнол рынке строчтельных материалов сибирских регионов

\begin{tabular}{|c|c|c|}
\hline Спрос & Типология & Предложение \\
\hline $\begin{array}{l}\text { Факторы, определяющие качество } \\
\text { жизни населения: доходы насе- } \\
\text { ления, желающие улучшить свои } \\
\text { жилищные условия, доступность за- } \\
\text { емных средств, процентная ставка, } \\
\text { средства государственной поддерж- } \\
\text { ки, уровень налоговой и админи- } \\
\text { стративной нагрузки }\end{array}$ & Эндогенные & $\begin{array}{l}\text { Факторы ресурсного потенциала: произ- } \\
\text { водственные мощности, запасы полезных } \\
\text { ископаемых, инфраструктура, технологи- } \\
\text { ческие инновации, себестоимость строи- } \\
\text { тельных материалов, процентная ставка, } \\
\text { доступность заемных средств, уровень } \\
\text { налоговой и административной нагрузки, } \\
\text { сезонность, производственная база }\end{array}$ \\
\hline $\begin{array}{l}\text { Факторы, которые в основном могут } \\
\text { принимать постоянную величину, } \\
\text { напр., ключевая ставка ЦБ РФ } \\
\text { или норма обеспеченности жильем } \\
\text { населения региона, и нечисленные } \\
\text { факторы: экологический, нацио- } \\
\text { нально-политический, этнокультур- } \\
\text { ный, инфраструктурный }\end{array}$ & Экзогенные & $\begin{array}{l}\text { Факторы опосредованного влияния: } \\
\text { наличие региональной жилищной и } \\
\text { региональной промышленной политики, } \\
\text { потребность сопряженных локальных } \\
\text { рынков, процессы межрегиональной } \\
\text { интеграции, глобализация рынков и тор- } \\
\text { говли, экологические факторы }\end{array}$ \\
\hline
\end{tabular}

В мировой практике сложились условия в виде государственных программных инструментов поддержки спроса домохозяйств не только в части порядка и условий долгосрочного кредитования приобретения жилья, но и в части развития принципов сочетания этого порядка с рыночными диспозитивными механизмами, поддерживающими экономический рост.

Для проведения всестороннего и глубокого анализа локального рынка необходимо не только сопоставление величин спроса и предложения, но и системная взаимосвязь с потоками капитала как материально-финансовым средством, являющимся ресурсом, обеспечивающим блага. В трудах В. Петти, Ф. Кенэ, Д. Рикардо, А. Смита, К. Маркса, Кейнса, Э. фон Бём-Баверка, Е. Е. Слуцкого, М. И. Туган-Барановского, Г. А. Харазова сформировались основные положения (принципы) воспроизводственного подхода, который позволяет рассматривать спрос и предложение с позиции потоков капитала, а потенциал региона как ресурс, являющийся резервом установления равновесия и достижения эффективности. Поэтому в целях совершенствования методического инструментария анализа локального рынка строительных материалов для обеспечения сбалансированного регионального развития предлагается использовать интегрирующее свойство воспроизводственных процессов через систему сопряженных локальных рынков про-

\section{Baikal Research Journal}


дукции и ресурсов региона. Формирование локального рынка стройматериалов сибирских регионов преследует цель усовершенствование снабжения строительного комплекса на базе возобновления естественно-ресурсного, производственного и трудового потенциала отрасли, улучшения финансовых взаимоотношений хозяйствующих субъектов $[9$, с. $65 ; 10$, с. $242 ; 11$, с. 56$]$. Таким образом, можно сформулировать следующие принципы территориальной локализации зон эффективной взаимодействия субъектов локальных рынков:

- наличие потенциала развития территории, в т. ч. за счет формирования и функционирования локального рынка местных стройматериалов;

- наличие структуры платёжеспособного спроса в соответствии с пространственно локализованным предложением;

- наличие современных средств выбора форм и способов предоставления государственной поддержки.

В предлагаемой методике экономической оценки локального рынка индустриального домостроения региона в целях управления, сбалансированность определяется через комплементарное сочетание трёх последовательных этапов. Предложено на первом этапе оценить потенциал развития отрасли по предложенной системе показателей с выявлением эндогенных и экзогенных факторов. Особенностью второго этапа является оценка параметров платежеспособного спроса. Алгоритмом третьего этапа является анализ (с использованием экономико-математического моделирования) возможного сценария развития отрасли индустриального домостроения в соответствии с выявленными параметрами платежеспособного спроса в целях обеспечения сбалансированного развития региональной экономики на основе методологии оптимального управления с использованием критериев локальной оптимальности [12, с. 82].

На первом этапе оценка общего потенциала развития отрасли проводится по формуле:

$$
\Pi_{\Sigma}=\left(\Pi_{\text {ТРУД }}+\Pi_{\text {РЕС }}+\Pi_{\Pi Р}+\Pi_{\text {ИНВ }}\right)\left(1+\frac{\Pi_{\text {ИНН }}+\Pi_{\text {эКОЛ }}+\Pi_{\text {ИНФР }}}{100}\right)
$$

$\Pi_{\text {ТРуд }}=\sum_{i=1}^{n} \Phi B i \cdot Ч i$, где

$\Phi B$ - показатель фондовооруженности $i$-го предприятия отрасли индустриального домостроения региона;

$\Psi$ - показатель численности занятых $i$-го предприятия отрасли индустриального домостроения региона;

$n$ - объем (количество субъектов) отрасли индустриального домостроения региона.

$$
\Pi_{P E C}=\sum_{i=1}^{n} Ц \Pi И i \cdot 3 i \cdot k, \text { где }
$$

ЦПИ - средняя цена добытого полезного ископаемого в целике (в начальной кондиции) $i$-го предприятия отрасли индустриального домостроения региона;

3 - запасы нерудных полезных ископаемых $i$-го предприятия отрасли индустриального домостроения региона;

$k$ - экономически эффективный коэффициент вскрыши

$n$ - объем (количество субъектов) отрасли индустриального домостроения региона.

$$
\Pi_{\Pi P}=\sum_{i=1}^{n} \Phi E i \cdot k i, \text { где }
$$

$\Phi E-$ показатель фондоёмкости $i$-го предприятия отрасли индустриального домостроения региона;

$k$ - коэффициент загрузки $i$-го предприятия отрасли индустриального домостроения региона;

\section{Baikal Research Journal}


$n$ - объем (количество субъектов) отрасли индустриального домостроения региона.

$\Pi_{\text {инв }}=\sum_{i=1}^{n} И i \cdot \Gamma \Pi i$, где

И - объем инвестиций $i$-го предприятия отрасли индустриального домостроения региона;

ГП - объем государственной поддержки инвестиционной деятельности і-го предприятия отрасли индустриального домостроения региона;

$n$ - объем (количество субъектов) отрасли индустриального домостроения региона.

В соответствии с принятым методическим подходом, показатель качественных факторов рассчитывается как средняя геометрическая из индексов изменения отдельных показателей состояния и развития инновационного, экологического и инфраструктурного факторов:

$$
\Pi_{и н B}=\sqrt[n]{\Pi_{i=1}^{n} \Pi_{И н B i}}, \text { где } \Pi_{И н в i}-\text { качественные показатели, характеризующие }
$$

отдельные компоненты инновационного потенциала; $n-$ количество показателей.

$\Pi_{\text {экол }}=\sqrt[n]{\Pi_{i=1}^{n} \Pi_{\text {эколi }}}$, где $\Pi_{\text {эколi }}$-качественныепоказатели, характеризующие отдельные компоненты экологического потенциала; $n-$ количество показателей.

$$
\Pi_{\text {инФР }}=\sqrt[n]{\Pi_{i=1}^{n} \Pi_{\text {ИНФРi }}}, \text { где } \Pi_{\text {ИНФРi }} \text { - качественные показатели, характери- }
$$

зующие отдельные компоненты инфраструктурного потенциала; $n-$ количество показателей.

Опытом сибирских регионов выявлено, что эффективным инструментом реализации потенциала строительной отрасли является система программ воспроизводства и расширения жилищного фонда региона. Поэтому вторым этапом предлагаемой методики оценки локального рынка индустриального домостроения является всесторонняя оценка параметров платежеспособного спроса региона $[13$, c. 35]. Учет именно жилищного фактора в структуре спроса на локальном рынке позволяет добиться большей репрезентативности, так как в структуре строительной отрасли три четверти принадлежит именно жилищному строительству, что влияет, в конечном счете, на качество жизни $[14$, с. 25]. Для того чтобы предметно оценивать влияние факторов на изменение текущего спроса и предложения, и, как следствие, конъюнктуру локального рынка, следует руководствоваться обобщенной типологией. В [4, с. 179] представлены виды и факторы спроса, и обосновано, что кроме представленной группировки факторов в табл. 1, следует выделить, в соответствии с современными исследованиями, один системный универсальный фактор - потенциал, который, трансформируясь в жилищные инвестиции, генерирует рост спроса.

Разработанные в настоящем исследовании средства формирования стратегии сбалансированности развития экономики сибирских регионов через факторы формирования спроса и предложения на локальных рынках, позволяют адаптировать предлагаемую в [6, с. 119] методику исследования локальных рынков строительных материалов в отношении регионов СФО. Условием реализации методики является переход роли государственных органов от регулятора и наблюдателя к активному игроку на рынке в силу их имманентного права принимать решение об использовании ресурсного потенциала. Особенностью и преимуществом предлагаемой методики является то, что результаты моделирования спроса и предложения на основе модели сбалансированности, позволяют формализовать большой объем разнородных данных в условиях их неполноты и выступает ключевым фактором постановки и решения задач оптимизационного управления.

\section{Baikal Research Journal}


Апробация разработанной методики проведена на примере одного из сибирских регионов - Республики Хакасия (далее - PX), для чего проанализирован потенциал отрасли стройиндустрии $\mathrm{PX}$, которая относится к структурообразующим. На этот элемент региональной индустрии приходится более 7 \% ВРП республики. Влияние уровня развития стройиндустрии на социально-экономическое положение также велико, так как на ее предприятиях трудоустроены около $15 \%$ населения. В 2016-2017 гг. отрасль и соответствующие локальные рынки были драйверами нахождения региона в числе лидеров среди регионов СФО по жилищному строительству. За 9 мес. 2017 г. РХ по вводу жилья оказалась одной из пяти регионов СФО, которые показали рост по сравнению с аналогичным периодом прошлого года (по РX составил $114,6 \%{ }^{2}$. Вместе с тем индикаторы статистики справедливо указывают на необходимость смены модели регионального роста. Уровень загрузки производственных мощностей строительных организаций в 2017 г. увеличился с 59 \% в I квартале до 64 \% в IV квартале. Однако индекс предпринимательской уверенности строительных организаций в течение 2017 г. снижался с «-19 \%» в I квартале, до «-38 \%» в IV квартале, в числе основных факторов - недостаток заказов на работы и высокая цена на строительные ресурсы $^{3}$. В соответствии со Стратегией РФ ${ }^{4}$, СФО является избыточным по производству цемента и асбестоцементных изделий, но дефицитным по листовому стеклу, строительной извести, изделий из гипса и керамическому кирпичу.

По результатам экспертного исследования состояния локального рынка строительных материалов РX выявлены следующие эндогенные и экзогенные факторы: разрыв производственно-экономических связей, снижение емкости внутреннего рынка и сокращение уровня платежеспособного спроса, падение уровня инвестиций в основной капитал предприятий отрасли, рост тарифов естественных монополий. Выявленные факторы формирования и функционирования локального рынка строительных материалов показывают специфику развития стройиндустрии не только в отраслевом, но и в территориальном аспектах, что подтверждает репрезентативность анализа локального рынка PX в целях исследования возможной применимости методики для других сибирских регионов.

Расчетные данные по оценке потенциала и спроса необходимы для выявления резервов сбалансированности развития локального рынка индустриального домостроения по выделенным компонентам факторов, которые для условий PX сгруппированы в табл. 2.

Таблица 2

Выявление резервов сбалансированности локального рынка индустриального долостроения в Республике Хакасия по выделенныл колпонентам

\begin{tabular}{|c|c|c|c|c|c|}
\hline $\begin{array}{c}\text { Фак- } \\
\text { тор }\end{array}$ & $\begin{array}{l}\text { Группа повышен- } \\
\text { ных значений ком- } \\
\text { понентов факторов }\end{array}$ & $\begin{array}{c}\text { Группа пониженных } \\
\text { значений компонен- } \\
\text { тов факторов }\end{array}$ & Отклонение & $\begin{array}{c}\text { Коэффициенты } \\
\text { регрессии }\end{array}$ & $\begin{array}{c}\text { Влияние } \\
\text { факторов } \\
\text { на отклонение }\end{array}$ \\
\hline \multicolumn{6}{|c|}{$\begin{array}{c}\text { уравнение регрессии по потенциалу } \\
y=0,661+0,275 x_{1}+1,850 x_{2}+0,690 x_{3}+5,612 x_{4}+0,650 x_{5}+0,410 x_{6}+0,570 x_{7}\end{array}$} \\
\hline$x_{1}$ & 1,175 & 1,010 & 0,165 & 0,275 & 0,045 \\
\hline$x_{2}$ & 1,527 & 1,076 & 0,451 & 1,850 & 0,834 \\
\hline
\end{tabular}

2 О жилищном строительстве в январе-сентябре 2017 г. URL: http://www.gks.ru/bgd/free/ b04_03/IssWWW. exe/Stg/d03/220.htm.

${ }^{3}$ Деловая активность строительных организаций Республики Хакасия в 2017 году / Красноярскстат. 2017. 26 дек.

${ }^{4}$ Стратегия развития промышленности строительных материалов на период до 2020 года и дальнейшую перспективу до 2030 года : утв. распоряжением Правительства РФ от 10 мая 2016 г. № 868-р // Собрание законодательства РФ. 2016. № 20. Ст. 2863.

\section{Baikal Research Journal}


Окончание табл. 2

\begin{tabular}{|c|c|c|c|c|c|}
\hline $\begin{array}{l}\text { Фак- } \\
\text { тор }\end{array}$ & $\begin{array}{c}\text { Группа повышен- } \\
\text { ных значений ком- } \\
\text { понентов факторов }\end{array}$ & \begin{tabular}{|c|} 
Группа пониженных \\
значений компонен- \\
тов факторов \\
\end{tabular} & Отклонение & $\begin{array}{c}\text { Коэффициенты } \\
\text { регрессии }\end{array}$ & $\begin{array}{c}\text { Влияние } \\
\text { факторов } \\
\text { на отклонение }\end{array}$ \\
\hline$x_{3}$ & 1,158 & 0,938 & 0,220 & 0,690 & 0,152 \\
\hline$x_{4}$ & 1,630 & 0,855 & 0,775 & 5,612 & 4,349 \\
\hline$x_{5}$ & 1,002 & 0,616 & 0,386 & 0,650 & 0,251 \\
\hline$x_{6}$ & 1,091 & 0,473 & 0,618 & 0,410 & 0,253 \\
\hline$x_{7}$ & 1,107 & 0,547 & 0,560 & 0,570 & 0,319 \\
\hline \multicolumn{5}{|c|}{ интегральное значение } & 0,170 \\
\hline \multicolumn{6}{|c|}{$\begin{array}{l}\text { уравнение регрессии по спросу } \\
x_{2}-0,716 x_{3}-73,891 x_{4}-2,247\end{array}$} \\
\hline$x_{1}$ & 1,980 & 1,220 & 0,760 & 0,066 & 0,050 \\
\hline$x_{2}$ & 1,060 & 0,860 & 0,200 & 0,488 & 0,098 \\
\hline$x_{3}$ & 1,000 & 0,990 & 0,010 & 0,716 & 0,007 \\
\hline$x_{4}$ & 1,410 & 0,330 & 1,080 & 73,891 & 79,802 \\
\hline$x_{5}$ & 3,190 & 1,220 & 1,970 & 2,247 & 4,427 \\
\hline$x_{6}$ & 6,230 & 0,300 & 5,930 & 1,689 & 10,016 \\
\hline \multicolumn{5}{|c|}{ интегральное значение } & 0,035 \\
\hline
\end{tabular}

Таким образом, по табл. 2 видно, что емкость потенциального наполнения факторов потенциала отрасли больше, чем возможный потенциал роста спроса за счет всех источников. Это означает, что по результатам оценки спроса и предложения на локальном рынке будет наблюдаться дисбаланс в сторону превышения предложения. В условиях снижения деловой активности производителей необходимо рассмотреть возможность дополнительной реализации программ предоставления государственной поддержки спроса.

На основе полученных моделей по результатам регрессионного анализа с разной степенью адекватности можно прогнозировать средний уровень развития потенциала отрасли. Под развитием в математическом смысле понимается изменение во времени объема производства, территориальной структуры и численности населения.

Таким образом, на основании результатов первых двух этапов проведения и апробации методики анализа локальных рынков региона обосновано применение системы управления воспроизводством и расширением жилищного фонда в качестве инструмента развития предприятий стройиндустрии.

Разработанная для исследования локальных рынков факторно-ресурсная методика посредством анализа жилищного воспроизводства выявила резервы повышения ресурсного потенциала локального рынка строительных материалов PX через систему сопряжённых локальных рынков для удовлетворения растущего жилищного спроса.

Выявленный резерв показывает обоснованную величину ресурсного потенциала, который иллюстрирует ситуацию на локальном рынке строительных материалов и стройиндустрии $\mathrm{PX}$, и может быть использован коммерческими службами соответствующих хозяйствующих субъектов при разработке сбытовых программ, а также органами бюджетного планирования местных властей для увеличения потенциала государственных программ воспроизводства и расширения жилищного фонда региона при привлечении бюджетных средств. Это становится особенно

\section{Baikal Research Journal}


актуальным при увеличении доли ветхих и аварийных домов в общей структуре жилищного фонда региона.

Экономическое значение заключается в том, что резерв для субъекта управления становится четким ориентиром в стоимостном выражении для принятия решений по возможности реализации ресурсного потенциала, и на сколько платёжеспособный спрос возможно в конкретных условиях реализовать за счет всех источников, чтобы покрыть выявленный резерв предложения [15, с. 83]. Такая постановка оптимизационной задачи обосновывает следующий шаг моделирования.

Третьим этапом задается оптимизационная задача как модель для анализа возможного сценария развития отрасли индустриального домостроения в целях обеспечения сбалансированного развития региональной экономики. После оценки потенциала отрасли и оценки платежеспособного спроса на локальном рынке региона, формируется многокритериальная модель оптимизации параметров развития локального рынка региона с использованием критериев локальной оптимальности:

- максимизации реализации ресурсного потенциала региона

- максимизации удовлетворения платежеспособного спроса

- максимизации маржинальной прибыли предприятий индустриального домостроения

Математически данная задача описывается следующими критериями оптимальности:

$$
F \rightarrow\left\{\begin{array}{l}
\sum_{j=1}^{m} q_{j}-d \cdot h \rightarrow \min \\
\sum_{j=1}^{m} q_{j}-u \rightarrow \max \\
x_{i} \max -\sum_{j=1}^{m} q_{j} \rightarrow \max \\
M=f\left(x_{1}, x_{2}, \ldots, x_{i}\right) \rightarrow \max
\end{array} .\right.
$$

В качестве управляемых переменных для решения задачи и записи ограничений и критериев используются следующие введенные обозначения: $q_{j}$ - объем ввода жилья по технологии $j ; d-$ среднедушевые доходы населения; $h-$ численность населения региона; $u$ - инвестиции; $k$ - объем средств предоставления государственной поддержки в общем объеме на реализацию программ развития в рамках стратегии; $\mathrm{z}_{i j}$ - объем сырья вида $i$ для производства строительных работ по технологии $j ; p_{i j}^{h}$ - цена реализации на локальном рынке продукции отрасли индустриального домостроения; $Z$ - затраты на сырьевые ресурсы; $C$ денежные средства на покупку ресурсов (ограничение на объем финансовых ресурсов); имеющиеся производственные мощности для выпуска продукции вида $i$ для производства строительных работ по технологии $j ; M-$ маржинальная прибыль; $m$ - количество отраслей стройиндустрии региона.

Ограничения модели имеют вид:

$$
\begin{aligned}
& Z \leq C \\
& Z_{i j} \geq 0 \\
& \sum u_{i j} \geq \sum_{j=1}^{m} q_{j} p_{i j}^{h}-C+k \\
& d \cdot h+k \geq \sum_{j=1}^{m} q_{j} p_{i j}^{h}-Z+u-k .
\end{aligned}
$$

\section{Baikal Research Journal}


На основе предложенных экономико-математических моделей возможно представление мультипликативного эффекта сбалансированного развития локального рынка на регион в целом. Для апробации и адаптации оценки такого влияния проанализирован основной стратегический план развития $\mathrm{PX}^{5}$ (далее - Стратегия PX), в которой в качестве целевых результативных показателей установлены:

- рост валового регионального продукта на душу населения - в 2,2 раза;

- роста объема отгруженной промышленной продукции на душу населения в 2,3 раза;

- рост собственных доходов республиканского бюджета - в 2,0 раза;

- рост среднемесячной номинальной заработной платы - в 1,9 раза;

- общая площадь жилых помещений, приходящаяся в среднем на одного жителя $-32 \mathrm{м}^{2}$.

На основе фактических данных за период 2005-2017 гг. по 29 показателям PX проведен прогноз их значений на период до 2030 года с использованием метода экстраполяции данных. Количественная интерпретация эффектов характеризует вклад отрасли индустриального домостроения в развитие региона до 2030 г. - он составит по отдельным показателям от 25,9 до 73,9 \% (табл. 3 ).

Таблица 3

Количественная интерпретация эффектов вклада отрасли индустриального домостроения в развитие Республики Хакасия

\begin{tabular}{|l|r|r|r|r|}
\hline \multicolumn{1}{|c|}{ Показатель } & 2010 & 2015 & 2020 & 2030 \\
\hline Инвестиции в основной капитал & 40,1 & 43,1 & 57,2 & 60,8 \\
\hline Объем отгруженной промышленной продукции на душу населения & 25,4 & 25,6 & 26,0 & 26,4 \\
\hline Собственные доходов республиканского бюджета & 24,9 & 25,1 & 25,5 & 25,9 \\
\hline Среднемесячная номинальная заработная плата & 36,1 & 36,4 & 37,0 & 37,5 \\
\hline $\begin{array}{l}\text { Общая площадь жилых помещений, приходящаяся в среднем на } \\
\text { одного жителя }\end{array}$ & 61,2 & 61,6 & 67,1 & 73,9 \\
\hline Потенциал в виде прогнозной оценки ВРП отрасли & 35,5 & 36,2 & 39,3 & 41,0 \\
\hline
\end{tabular}

Как видно из табл. 3, к концу прогнозируемого горизонта наибольший вклад в развитие значений республиканских показателей будет по показателям инвестиций в основной капитал $(60,8 \%)$ и общая площадь жилья на одного жителя республики $(73,9$ \%). Таким образом, подтверждается важность развития локального рынка индустриального домостроения по предложенным инструментам для социально-экономического развития РX. К концу 2030 г. мультипликативный эффект развития локального рынка в общем росте республиканского потенциала составит 41,0 \% (такое значение может означать, что остальные структурообразующие отрасли $\mathrm{PX}$ имеют низкий потенциал для развития).

Полученная модель является инструментом расчета дополнительных инвестиций в сопряженные локальные рынки, позволяющих сгладить дисбаланс достижения целевых показателей стратегии развития. Положительный результат моделирования позволяет дать рекомендации по развитию интегрального эффекта от выявления и реализации резервов потенциалов спроса и предложения в схожих с PX конъюнктурных условиях развития сибирских регионов.

Анализ и интерпретация результатов моделирования, позволяют сделать промежуточный вывод о достаточности имеющихся и привлекаемых ресурсов для обеспечения оптимизации параметров развития локального рынка, влияющего на

${ }^{5}$ Стратегия социально-экономического развития Республики Хакасия до 2020 года : утв. постановлением Правительства Республики Хакасия от 25 окт. 2011 № 700 // Собрание законодательства РФ. 2010. № 33. Ст. 4444.

\section{Baikal Research Journal}


устойчивое сбалансированное развитие регионального хозяйства. В соответствии с определением, введенным в начале данного исследования, жилищные воспроизводственные процессы обеспечивают мультипликативный эффект управленческого воздействия выявленных резервов. Постепенный переход в моделировании от АРПСС к модели оптимизации параметров при существенной мультиколлинеарности с использованием методики факторно-ресурсного подхода, позволяет сделать прогноз с учетом всего массива факторов при предположении стационарности их общего суммарного влияния в будущем. С одной стороны, экономический смысл значений табл. 2 заключается в том, что оптимальность параметров резерва потенциалов спроса и предложения зависит от всей совокупности факторов, определяющих социально-экономическое развитие региона. С другой стороны сбалансированность достигается за счет оптимизации прогнозных значений потенциалов спроса и предложения. Таким образом, введение степени реализации фактора ресурсного потенциала в модель не снизило исследовательской ценности прогноза, следовательно, является важнейшим показателем интегральной эффективности.

Предложенная воспроизводственная модель сбалансированного развития локальных рынков регионов Сибири позволяет выбрать приоритетные локализованные зоны для комплексного освоения территорий в зависимости от степени развития потенциала. Таким образом, в исследовании были предложены:

- система показателей оценки потенциала отрасли и критерии оптимизации параметров развития соответствующего локального рынка;

- методика оценки локального рынка индустриального домостроения в регионе по критерию сбалансированности в целях управления;

- инструменты управления сбалансированным социально-экономическим развитием региона;

- группировка факторов, оказывающих влияние на спрос и предложение, их систематизация и система показателей оценки;

- применимость разработанной и апробированной на материалах Республики Хакасия методики в сибирских регионах.

Таким образом, разработанный в настоящем исследовании инструментарий формирования стратегии сбалансированности развития региональных экономик, учитывающие факторы формирования спроса и предложения на локальном рынке строительных материалов, позволяют адаптировать предлагаемую методику исследования локальных рынков в процессе формирования стратегии сбалансированности развития экономики сибирских регионов.

\section{Список использованной литературы}

1. Ивантер В. В. Структурно-инвестиционная составляющая долгосрочной экономической стратегии России / В. В. Ивантер // Общество и экономика. - 2017. - № 8. - С. 5-32.

2. Глазьев С. Ю. В «тысячу первый» раз о выборе между стратегиями социально-экономической деградации страны и современного народнохозяйственного развития / С. Ю. Глазьев // Российский экономический журнал. - 2016. - № 3. - С. 3-17.

3. Самаруха В. И. Проблемы экономической безопасности ресурсных регионов Сибири в контексте конкурентоспособности / В. И. Самаруха // Экономическая безопасность: стратегия взаимодействия государства и бизнеса : материалы региональной науч.-практ. конф. (г. Иркутск, 25 ноября 2014 г.). - Иркутск, 2015. - С. 160-165.

4. Галазова С. С. Рынок жилья: анализ современных моделей эффективной сбалансированности / С. С. Галазова, Т. Г. Краснова, А. С. Вильгельм // Вестник Адыгейского государственного университета. Серия 5: Экономика. - 2016. - № 3 (185). - С. 177-186.

5. Пузанов А. С., Косарева Н. Б., Полиди Т. Д., Туманов А. А. Анализ изменений жилищной обеспеченности и возможностей улучшения жилищных условий в период пере-

\section{Baikal Research Journal}


хода к рыночной экономике / Пузанов А. С. [и др.] // Уровень жизни населения регионов России. - 2012. - № 1. - С. 29-41.

6. Вильгельм А. С. Исследование текущего состояния и перспектив локального рынка строительных материалов в процессе формирования стратегии сбалансированности развития экономики региона / А. С. Вильгельм // Экономика и менеджмент систем управления. - 2017. - № 2.1 (24). - С. 116-121.

7. Васильева 3. А., Филимоненко И. В., Лукьянова А. А., Фалалеев А. Н. Роль локальных рынков в обеспечении устойчивости экономики региона при переходе к инновационной модели развития / 3. А. Васильева [и др.] // Вестник Сибирского государственного аэрокосмического университета им. академика М.Ф. Решетнева. - 2014. - № 5 (57). - С. $253-261$.

8. Светник Т. В. Стратегические решения по развитию отрасли строительства в регионе / Т. В. Светник // Актуальные тенденции развития мировой экономики : материалы междунар. науч.-практ. конф., Иркутск, 15-16 марта 2016 г. : в 2 ч. - Иркутск, 2016. - Ч. 1. C. $464-469$.

9. Батукова Л. Р. Методологическая проблема определения объекта управления инновационной модернизацией экономики региона сырьевой направленности / Л. Р. Батукова, Г. Я. Белякова // Логистические системы в глобальной экономике. -2014 . — № 4. — С. 59-65.

10. Шнипер Р. И. Региональные проблемы рынковедения: экономический аспект // Р. И. Шнипер, А. С. Новоселов. - Новосибирск : Наука, 1993. - 443 с.

11. Бернвальд А. Р. Региональные проблемы товарного обращения (в районах Сибири и Дальнего Востока) / А. Р. Бернвальд. - Новосибирск : Наука, 1984. - 207 с.

12. Чупров С. В. Нелинейные метаморфозы и инновационные возмущения в управлении развитием региональной промышленности / С. В. Чупров // Организатор производства. - 2016. - № 4 (71). - С. 76-86.

13. Бузырев В. В. Инновационные методы в организации и управлении индустриальным домостроением в современных условиях / В. В. Бузырев, А. В. Бузырев // Вестник факультета управления СПбГЭУ. - 2017. - № 1-2. - С. 34-40.

14. Астафьев С. А. Реформа регулирования жилищной сферы - назревшая необходимость / С. А. Астафьев, Г. В. Хомкалов, Б. М. Бедин // Актуальные тенденции развития мировой экономики : материалы междунар. науч.-практ. конф., Иркутск, 1516 марта 2016 г. : в 2 ч. - Иркутск, 2016. - Ч. 2. - С. 21-28.

15. Самаруха А. В. Стратегия устойчивого экономического роста регионов Сибири в условиях усиления процессов глобализации / А. В. Самаруха, В. И. Самаруха // Развитие российского общества: социально-экономические и правовые исследования. - М. : Наука, 2014. - C. 60-89.

\section{References}

1. Ivanter V. V. Structural and investment component of Russian long-term economic strategy. Obshchestvo i ekonomika = Science and Economy, 2017, no. 8, pp. 5-32. (In Russian).

2. Glazev S. Yu. For the "thousand first» time on the choice between strategies of socio-economic degradation of the country and modern economic development. Rossiiskii ekonomicheskii zhurnal = Russian economic Journal, 2016, no. 3, pp. 3-17.

3. Samarukha V. I. Problems of economic security of resource regions of Siberia in the context of competitiveness. Ekonomicheskaya bezopasnost': strategiya vzaimodeistviya gosudarstva i biznesa. Materialy regional'noi nauchno-prakticheskoi konferentsii. Irkutsk, noyabrya 25, $2014 \mathrm{~g}$. [Economic security: strategy of interaction between state and business. Materials of Regional Scientific and Practical Conference, Irkutsk, November 25, 2014 ]. Irkutsk, 2015, pp. 160-165. (In Russian).

4. Galazova S. S., Krasnova T. G., Vil'gel'm A. S. Housing market: analysis of modern models of effective balance. Vestnik Adygeiskogo gosudarstvennogo universiteta. Seriya 5: Ekonomika= Bulletin of the Adygeya State University. Series Economics, 2016, no. 3 (185), pp. 177-186. (In Russian).

5. Puzanov A. S., Kosareva N. B., Polidi T. D., Tumanov A. A. Analysis of changes in housing provision and opportunities for improving housing conditions during transition to market economy. Uroven' zhizni naseleniya regionov Rossii = Level of Life of the Population of Region of Russia, 2012, no. 1, pp. 29-41. (In Russian).

\section{Baikal Research Journal}


6. Vil'gel'm A. S. Investigation of current state and prospects of local market of construction materials in the process of forming a strategy for balanced development of regional economy. Ekonomika $i$ menedzhment sistem upravleniya = Economics and Management of Control Systems, 2017, no. 2.1 (24), pp. 116-121. (In Russian).

7. Vasil'eva Z. A., Filimonenko I. V., Luk'yanova A. A., Falaleev A. N. The role of local markets in providing stability of regional economy in the time of conversion to innovation model of development. Vestnik Sibirskogo gosudarstvennogo aerokosmicheskogo universiteta im. akademika M.F. Reshetneva = Bulletin of M. F. Reshetnev Siberian State Aerospace University, 2014, no. 5 (57), pp. 253-261. (In Russian).

8. Svetnik T. V. Strategic solutions for developing regional construction industry. Aktual'nye tendentsii razvitiya mirovoi ekonomiki. Materialy mezhdunarodnoi nauchno-prakticheskoi konferentsii, Irkutsk, 15-16 marta $2016 \mathrm{~g}$. [Current trends in development of world economy. Materials of International Research Conference, Irkutsk, Marsh, 2016]. Irkutsk, Baikal State University of Economics and Law Publ., 2016, vol. 1, pp. 464-469. (In Russian).

9. Batukova L. R., Belyakova G. Ya. Methodological problem of determining management object of innovation modernization in regional economy of raw materials. Logisticheskie sistemy $v$ global'noi ekonomike = Logistic Systems in Global Economy, 2014, no. 4, pp. 59-65. (In Russian).

10. Shniper R. I., Novoselov A. S. Regional'nye problemy rynkovedeniya: ekonomicheski aspekt [Regional problems of market science: an economic aspect]. Novosibirsk, Nauka Publ., 1993. $443 \mathrm{p}$.

11. Bernvald A. R. Regional'nye problemy tovarnogo obrashcheniya ( $v$ raionakh Sibiri $i$ Dal'nego Vostoka) [Regional problems of commodity circulation (in regions of Siberia and the Far East)]. Novosibirsk, Nauka Publ., 1984. 207 p.

12. Chuprov S. V. Nonlinear metamorphoses and innovative disturbances in managing development of regional industry. Organizator proizvodstva = Production Organizer, 2016, no. 4 (71), pp. 76-86. (In Russian).

13. Buzyrev V. V., Buzyrev A. V. Innovative methods in organization and management of industrial housing in current context. Vestnik fakul'teta upravleniya SPbGEU = Bulletin of Chair of Management of Saint Petersburg State University of Economics, 2017, no. 1-2, pp. 34-40. (In Russian).

14. Astafev S. A., Khomkalov G. V., Bedin B. M. Reform of housing regulation is the urgent necessity. Aktual'nye tendentsii razvitiya mirovoi ekonomiki. Materialy mezhdunarodnoi nauchno-prakticheskoi konferentsii, Irkutsk, 15-16 marta 2016 g. [Current trends in development of world economy. Materials of International Research Conference, Irkutsk, Marsh, 2016]. Irkutsk, Baikal State University of Economics and Law Publ., 2016, vol. 2, pp. 21-28. (In Russian).

15. Samarukha A. V., Samarukha V. I. Strategy of sustainable economic growth in Siberian Regions in terms of increasing globalization processes. Razvitie rossiiskogo obshchestva: sotsial'no-ekonomicheskie i pravovye issledovaniya [Development of Russian Society: Socio-Economic and Legal Research]. Moscow, Nauka Publ., 2014, pp. 60-89. (In Russian).

\section{Информация об авторах}

Самаруха Виктор Иванович - доктор экономических наук, профессор, профессор кафедры налогов и таможенного дела, заслуженный деятель науки Российской Федерации, заведующий лабораторией региональной экономики и финансов, Байкальский государственный университет, 664003, г. Иркутск, ул. Ленина, 11, e-mail: vis@isea.ru.

Краснова Татьяна Григорьевна - доктор экономических наук, профессор, ректор Хакасского государственного университета им. Н. Ф. Катанова, 655017, Республика Хакасия, г. Абакан, пр. Ленина, 90, корпус 2, e-mail: admeconom@mail.ru.

Вильгельл Александр Сергеевич - аспирант кафедры менеджмента Института экономики и управления Хакасского государственного университета им. Н. Ф. Катанова, 655017, Республика Хакасия, г. Абакан, пр. Ленина, 90, корпус 2, e-mail: asvilhelm@gmail.com.

\section{Authors}

Viktor I. Samarukha - Doctor habil. in Economics, Professor, Chair of Tax and Custom Affairs, Honored Worker of Science of the Russian Federation, Head of Laboratory of Regional

\section{Baikal Research Journal}


Economics and Finance, Baikal State University, 11 Lenin St., 664003, Irkutsk, e-mail: vis@ isea.ru.

Tatyana G. Krasnova - Doctor habil. in Economics, Professor, N. F. Katanov Khakass State University, 90 Lenin St., 655017, Abakan, e-mail: admeconom@mail.ru.

Alexander S. Vilgelm - PhD Student, Chair of Management, Institute of Economics and Management, N. F. Katanov Khakass State University, 90 Lenin St., 655017, Abakan, e-mail: asvilhelm@gmail.com.

\section{Для цитирования}

Самаруха В. И. Исследование факторов спроса и предложения на локальном рынке индустриального домостроения в процессе формирования стратегии сбалансированности развития экономики сибирских регионов / В. И. Самаруха, Т. Г. Краснова, А. С. Вильгельм // Baikal Research Journal. - 2018. - T. 9, № 1. - DOI : 10.17150/2411-6262.2018.9(1).4.

\section{For Citation}

Samarukha V. I., Krasnova T. G., Vilgelm A. S. Study of Supply and Demand Factors on Local Market of Industrial Housing Construction in Process of Forming a Strategy of Balanced Development of Economy in Siberian Regions. Baikal Research Journal, 2018, vol. 9, no. 1. DOI: 10.17150/2411-6262.2018.9(1).4. (In Russian).

\section{Baikal Research Journal}

